\title{
Die preek in die weegskaal
}

C J A Vos

Abstract

The sermon on the balance

The focus of this article is on the sermon in crisis. In this regard a variety of factors should be taken in consideration. The preacher, the communication process, the message, the listener, as well as his context, are of ultimate importance in dealing with this crisis.

Die preek in die krisis

Die preek is in 'n krisis. Dié bewering kry slegs betekenis indien die verskillende spelers en faktore in die krisis onderskei word. In die artikel word 'n poging aangewend om in 'n gesprek met die spelers te tree en om van die faktore kennis te neem. Die prediker, die kommunikasieproses, die boodskap, die hoorder en sy konteks is van belang ten einde iets van die preekkrisis te begryp.

Die eerste fokuspunt is die prediker en die wyse waarop hy met die preek omgaan. Sonder om alle predikers onder een kam te skeer, word 'n arsenaal besware teen predikers losgelaat. Dit moet in gedagte gehou word dat die preekoordrag geen sakrosante beskerming het nie. Hoorders en kykers word daagliks blootgestel aan teksomgang en -kommunikasie. Daarom meet en beoordeel hulle die preekoordrag aan die hand van die woordoordrag van openbare sprekers (politici, redenaars) en die beoordeling is nie altyd in die guns van die preekoordrag nie. Preke vertoon soms 'n gebrek aan patroon, tekstuur, sinsritme, woordvernuf en kommunikasievaardighede. Al dié en nog meer gebreke bemoeilik die luisterproses aansienlik. Die gevolg is dat die hoorder slegs met moeite en inspanning aan die tekskommunikasie kan deelneem.

Die taal waarin die sender (prediker) die boodskap kodeer, veroorsaak dikwels 'n "semantische Gerausch"1. Die geruis vind op verskillende wyses plaas. Aan die een kant kan die prediker die hoorder deur 'n oorinformasieaanbod oorweldig en aan die ander kant kan die hoorder deur eindelose herhalinge verveel word 2 . 'n Ewewig tussen informasie en redundansie is vir 'n sinvolle luister na preke onontbeerlik. 'n "Semantische Gerausch" kom ook voor waar die prediker en die hoorder in verskillende taalregisters praat ${ }^{3}$. Argaïese, teologiese, akademiese taal, swak taalgebruik kan verhinder dat die preek sy bestemming bereik. Wanneer daar in teologiese registers gepreek word, munt preke uit deur'n gebrek aan eietydse konkretisering. Die prediker het net die beitel van die woord om die Woord vir mense oop te breek. In dié proses moet hy sy instrument temper. Hy moct ag gee op elke klein woordjie sodat dit soos molekules in 'n glas wat met die vinger gevryf word, saam vibreer totdat ' $n$ klank so fyn en suiwer ontstaa-: dat geen matcricle vorm dit kan indam nie 4 . Wanneer dit nie gebeur nie, is die taal wat gebruik word nie geskik om die preek te laat kommunikeer nie.

Dikwels word die preek aangebied asof dit 'n skriftelike gebeure is. Die rede hiervoor lê natuurlik in die feit dat preke meestal 'n skriftelike ontstaan het en 
moeilik 'n vrye bestaan kan lei. Die gevolg is dat preke meer die vorm van 'n lesing as 'n vrye preek aanneem. Vir die kommunikasie van die preek is dit alles behalwe gunstig. Wat vasstaan is dat indien 'n preek op taalvlak misluk, bereik die boodskap nie sy bestemming (die hoorder) nie.

Die kommunikasie van die preek word voorts bemoeilik deur die rasionalistiese binding daarvan. In die post-reformatoriese skolastiek het die prediking ontaard in 'n formele en rigiede skema: "subtilitas intelligendi, subtilitas explicandi, subtilitas applicandi - careful understanding, explanation, and application" 5 van die Bybelse teks. Teen die einde van die Verligting het die vorm ontwikkel tot "An introduction... followed by the text, which in turn was reduced to a propositional topic, which was developed in a series of 'points' (often categorical), before the sermon ended in a conclusion" 6 . In die preke met punte word daar meestal van die een fokuspunt na die ander beweeg sonder om die samehang toe te lig of die beweging van die Bybelse teks in ag te neem. Punt vir punt word sake afgehandel.

Die tweede saak wat in die preekkrisis die aandag vra, is die kommunikasieproses. Hieronder is daar verskillende sake wat toegelig moet word. Kerkgangers het dikwels besware teen die preek as wyse van kommunikasie. Die besware moet teen die agtergrond van ons wêreld as 'n wye kommunikasienetwerk verstaan word. Daar is ' $n$ informasie-aanbod op alle lewensvlakke deur middel van boeke, tydskrifte, die radio, die televisie, die film, die video, strooibiljette, lesings en voordragte. Kommunikasie as 'n dinamiese proses maak van moderne leer- en oordragmetodes soos kursusse, seminare, gesprekke en leeskringe gebruik?.

In vorige eeue toe koerante nog nie daagliks, weekliks of maandeliks kommentaar op wêreldgebeure gelewer het nie, was die preek 'n uitstekende bron van informasie en opvoeding 8 . Tans stuit die preek as kommunikasievorm teen die werklikheid dat informasie, opvoeding, lering, vertroosting en vermaak op die oog en oor af soveel doeltreffender kan plaasvind.

Die preek as 'n duidelike vorm van eenrigtingverkeer kom in botsing teen die kommunikasieproses as dialoog 9 . Dialoog skep ruimte vir alle deelnemers se sieninge ${ }^{10}$. Dit beteken nie dat alle deelnemers met die preekgebeure saamstem nie, want hoewel dialoog op ooreenstemming gerig is, vind dit nie sy vertrekpunt daarin nie 11 . In die preek as eenrigtingverkeer is daar "... no dialogue, no listening by the speaker, no contribution by the hearer. If the congregation is on the team, it is as javelin catcher"12. Die vorm van die preek as normatiewe betoog van een persoon, wat met gesag vanuit 'n hoë posisie praat, is nie lewensvatbaar nie ${ }^{13}$. Die gesag van die preek lê buitendien nie primêr in die persoon van die prediker nie, maar in die Woord wat hy verkondig.

'n Derde saak wat vir die bespreking van die preekkrisis van belang is, is die vraag na die boodskap. Die Bybel is God se boek oor Homself, maar daar word gekla oor die verborge God14; die swygende God15. Die twintigste eeu word telkens getipeer as 'n tyd van Godsverduistering of Godskemering ${ }^{16}$. Die term fokus op 'n bepaalde punt, naamlik die verdwyning van God uit die ervaringswêreld van die hedendaagse mens ${ }^{17}$. Aan die ervaring het die mens alleen maar skuld - individueel en kollektief.

Nie net is, word gesê, God swygend verborge nie, maar die tydlose Bybelse boodskap is ook irrelevant. Dit kom uit 'n Oosterse milieu en werklikheidsbeskouinge wat eeue verwyderd is van ons moderne wêreld en sy sieninge. Hiermee word nie ontken dat die Bybel die mens van vervloë tyd aangespreek en gehelp het 
nie. Die gevolg is dat die nood en die vrae van die hedendaagse mens verbygegaan word. Hoe kan die preek mense help in hulle angs, armoede en lyding? Watter woord het die Bybel oor die ekologiese krisis ${ }^{18}$ ? Hoe kan die Bybel bydra om oplossings vir teenoorgestelde politieke modelle te bied? Mense worstel met keuses en waardes. Hoe kan die Bybel mense help om vandag religieus-etiese keuses te maak? Is die Bybelse etiek nie kasuistick nie? Bots dit nie lynreg met die vryheid van elke mens nie? Kan 'n ou boek 'n steeds wisselende en veranderende waardestelsel normeer en reguleer? Moet elke tyd nie ou waardes afbreek en nuwe waardes skep vir sy tyd en volgens sy behoeftes nie? Die betowerende krag van veral die televisie oorweldig menige kyker met waardes wat soms lynreg teenoor die christelike etiek staan.

'n Vierde saak wat 'n beduidende rol in die preekkrisis speel, is die hoorder en sy wêreld. Die hoorder leef in 'n godsdienstige, sosiale en geesteskonteks ${ }^{19}$. Al drie die kontekste het ' $n$ invloed op die wyse waarop hy die boodskap ontvang en verwerk. Die liturgie bied die godsdienstige konteks waarbinne die preek gelewer word ${ }^{20}$. Die konteks van die preek is dikwels vaal, kleurloos en sonder verbeelding. Die liturgie is soms so voorspelbaar dat die hoorder deur verveling oorweldig kan word. Hierteenoor word hoorders byna elke dag aan die skeppende en (soms) verbeeldingryke visuele liturgiek van die televisie blootgestel.

Die hoorder se godsdienstige konteks word verder gevorm deur sy godsdienstige ervarings van kindsbeen af. Die hoorder kom nie met leë hande kerk toe nie. Hy dra sy godsdienstige en kulturele erfenis, sy godsdienstige en politieke oortuigings, sy lewenservaringe en sy belydenisse met hom saam.

Die hoorder se godsdienstige wêreld is nie tot sy kultiese wêreld beperk nie. In sy alledaagse wêreld is daar volop tekens van religiositeit. Die mens hou sy sekulêre heilandsfigure wat sy angs moet besweer byderhand. Calvyn het reeds die mens bestempel as 'n fabrica idolonum, 'n afgode-fabriek. Die mens mag God verwerp, maar aanbid sal hy aanbid - al is dit 'n bankbalans. Sommige praat van die Amerikaanse triniteit van "sex, car and career".

Verskuiwings in die mens se leefwêreld het ook 'n invloed op sy godsdienstige konteks. Dit was deur die eeue die geval. 'n Klassieke voorbeeld hiervan is die vestiging van die corpus Christianum waardeur God se plek deur die staat verseker is. Konstantyn se oorwinning oor Maximus by die Milviese Brug digby Rome, op 28 Oktober in die jaar $312 \mathrm{n} \mathrm{C}$ was die voorloper van die Edik van Milaan (313) wat vir die eerste keer aan Christene 'n geloofsvryheid gelykstaande aan dié wat die heidense kultusse geniet het, gewaarborg het. Hierop het verskeie maatreëls gevolg wat die Christendom in toenemende mate teenoor die ander godsdienste bevoordeel het. Die hoogtepunt van die proses was in die jaar 380 toe Keiser Theodosius die ortodokse geloof, soos deur die biskop van Rome en die patriarg van Alexandrië verteenwoordig, as die enigste godsdiensvorm in die Romeinse ryk erken het. Heidene en Christenketters is vervolgens oor dieselfde kam geskeer en tot aartsvyande verklaar. Die leer van die drie-eenheid byvoorbeeld, volgens ortodokse interpretasie, het staatswet geword. Wie hom hierteen verset, is nie net ketter nie maar tegelykertyd ook anargis. Dit was vanselfsprekend en veilig om lid van die kerk te wees ${ }^{21}$. Die toedrag van sake het die Christendom te tuis in die wêreld gemaak en hom van sy vreemdelingskap beroof. God het ook te vanselfsprekend en voorhande geword. God se koninkryk kan nie met staatsgrense saamval nie. Sy koninkryk omvat die aarde en is groter as enige politieke grense. 
Verskuiwinge in die mense se sosiale wêreld beïnvloed die mens se ervaring van sy godsdienstige wêreld. Ekonomiese groei of 'n gebrek daaraan, die beskikbaarheid van arbeid aldan nie het ' $n$ invloed op die mens se ervaring van sy godsdiens. Armoede, fisiese en geestelike lyding, werkloosheid het 'n uitwerking op mense se Godservaring. Die invloed van politieke mag is ook nie neutraal nie. Wanneer politieke magte vir 'n groep of volk gunstig is, kan dit makliker wees om God as naby te ervaar. Maar die verskuiwing van politieke kragte kan 'n duister ervaring van God se teenwoordigheid meebring. 'n Sosiologiese ontwrigting kom die skerpste aan die lig op die gebied van voedsel, skuiling en seksualiteit. As dit ontbreek, soek die mens na ander alternatiewe.

Die hoorder leef nie net in 'n godsdienstige en sosiale konteks nie, maar ook binne 'n geestesklimaat. In die loop van die eeue het verskillende geestesbeweginge hulle invloed laat geld. Die beweginge is nie tydloos nie, maar kontekstueel in die sin dat dit'n bepaalde weerkaatsing van die verstaan van die mens in sy wêreld is. In elke bepaalde beweging lê daar slegs 'n verstaansbrok van die mens in sy werklikheid. Dit is eers wanneer al die brokke byeen gebring word dat ons iets van die mens in sy wêreld kan begryp.

Die geestesbeweging wat sedert die Renaissance en die Verligting in die Westerse wêreld vaardig geword het, vind vandag universele geldingskrag in die hele wêreld. Afgesien daarvan dat miljoene mense nie regtig hiervoor ryp is nie, bring dit die mensheid as geheel tot 'n nuwe selfverstaan, met ingrypende gevolge wat die hele lewe raak. Daar sal in die prediking daarmee rekening gehou moet word dat die nuwe mens aan die einde gekom het van die Westerse heerskappy, die koloniale tydperk, alle vorme van outokrasie en verdrukking, outoritêre gesag en ongekontroleerde waarheidsaansprake $e^{22}$.

Vir die Christendom en die kerk beteken die nuwe geesteskonteks die verlies van die soort politieke beskerming en vanselfsprekendheid wat dit sedert die vierde eeu in die Westerse wêreld geniet het. Die kerk moet in 'n klimaat van godsdiensvryheid en sekularisasie op gelyke voet meeding met ander godsdienste en denkrigtings wat om gehoor vra. Die stryd om die waarheid kan nie met die swaard of deur wetgewing besleg word nie. Die swaard van die Woord moet in 'n pluralistiese nuwe wèreld oorwinnings behaal.

'n Mens kan nie die wêreld tot stilstand bring om af te klim nie, of die klok terugdraai nie. 'n Mens durf jouself ook nie in 'n ghetto terugtrek om iets van die verlede solank as moontlik te bewaar nie. As Christene mag mense ook nie die godsdiens tot die private sfeer van die persoonlike of huislike binnekring beperk, en die stryd om die kerstening van die gemeenskap prysgee nie. Dit is die gevaar van 'n eensydige vorm van piëtisme. Dit is net op die individuele mens gerig. Die gevolg hiervan is wêreldontvlugting. In die prediking moet die evangelie op so 'n wyse hanteer word dat dit die heerskappy van God in die wêreld proklameer, en die waardes daarvan vestig.

Die posisie van die preek word ook nog nadelig getref deur die uiters geringe effek daarvan op die hoorder ${ }^{23}$. Ondersoeke het aan die lig gebring dat min mense ' $n$ preek kan navertel. Wat nog te se daarvan leef en daarvolgens handel ${ }^{24}$. Enkele gedagtes en ' $n$ beeld of twee word saamgevat en vermeng met die hoorder se eie leefwêreld. Die geringe effek van die preek het te doen met die feit dat die hoorder soms (meestal) in die preekgebeure geëkskommunikeer word. 'n Hoordershermeneutiek bied ' $n$ insig in die faktore wat die luisterproses belemmer en 
bevorder ${ }^{25}$. Van der Ven ${ }^{26}$ het enkele faktore wat kommunikasie in die weg staan op kaart gebring. Die faktore kan ook in die luister na die preek in berekening gebring word. Dit moet steeds in gedagte gehou word dat kommunikasie in 'n gebroke wêreld plaasvind. Die gebroke wêreld lè 'n beperking op die proses van kommunikasie. Die eerste faktor wat 'n invloed op kommunikasie het, is die verskynsel van demografie. In die mate wat deur die proses van verstedeliking die aantal mense pro kwadraatkilometer toeneem, neem die neiging ook toe dat waardes in die algemeen en religieuse waardes in die besonder as privaatsake beskou word 27 . Die nadelige effek op die preek is dat mense nie maklik daaroor praat nie. Hulle bewaar dit eerder in hulle harte. 'n Tweede faktor wat 'n uitwerking op die kommunikasie van die preek het, is politieke faktore. Die uitwerking van politieke kragte word nie by die kerkdeur geweer nie 28 . Die invloed van die politiek van verskillende tydvakke word ook in preke geresoneer. In die hoogbloei van die ideologie van apartheid is die kontoere van die ideologie ook in preke gesien. Dieselfde is waar van preke waarin die idioom van bevryding neerslag gevind het. In ons dag tree 'n politieke pluraliteit skerper na vore. Die gevaar is dat daar in preke ' $n$ partypolitieke keuse gemaak kan word. Dit is die soort keuses wat sommige hoorders kan vervreem. In preke moet die septer wel oor politieke grense geswaai word, maar dan mag ideologiese voorkeure nie uitgeoefen word nie. Dit gaan altyd om 'n pleit vir God se heerskappy oor alle magte. 'n Verdere faktor wat kommunikasie in die weg kan staan, is kulturele faktore. Van der Ven ${ }^{29}$ bied die volgende verduideliking van die kulturele faktore: Kulturele faktore beteken dat die lede van 'n gemeenskap hulle aan gemeenskaplike doelstellings, opvattinge en waardes oriënteer, hulle daaraan verbind, hulle rol en funksies daaraan ontleen en hulle handelinge daardeur laat normeer. Dit beteken verder dat die lede van 'n gemeenskap hierdie doelstellings, opvattings en waardes onverkort aan die nageslag met die hulp van 'n daarvoor toegeëiende sosialiseringsproses oorlewer, wat op die internalisering daarvan gerig is. Ten slotte onderwerp die lede van 'n gemeenskap hulle op grond van sosiale kontrole aan sanksies indien hulle van die opvattinge afwyk. Die kulturele konsensus wat op die wyse in stand gehou word, word op kulturele konvensies en adopsies gebaseer ${ }^{30}$. 'n Vertaling van die kulturele faktore met die oog op die preek vind plaas wanneer die Bybel, die tradisie en die ampsgesag as instrumente dien om die eenheid van die gemeentelede te bewaar en te versterk. Hierdie vorm van kulturele konvensie en adopsie staan die konsep van kommunikasie in die weg31. Die rede hiervoor is dat 'n tradisionele verstaan van die Bybel, die neergelegde tradisie en 'n gefikseerde ampsbeskouing 'n kreatiewe interpretasie en konkretisering van die Bybel verhinder. Dit is juis 'n kreatiewe vertolking en konkretisering wat die kommunikasie van die preek bevorder.

Die preek kommunikeer op verskillende vlakke. Daarom moet daar in die preekproses voldoende ruimte vir die intellek, die gevoel en die wil geskep word. Die inhoudsaspek van kommunikasie konsentreer op die intellektuele proses, terwyl die verhoudingsaspek van kommunikasie op die emosionele gebeure fokus ${ }^{32}$. 'n Ewewig tussen die intellektuele en emosionele aspekte vra dat daar met die proses van kognitiewe dissonansie rekening gehou moet word. Onder kognitiewe dissonansie word verstaan dat die mens se emosies nie altyd parallel met sy rasionaliteit loop nie en daarom moet die argumente aangepas word ${ }^{33}$.

In die preek moet die prediker met 'n verskeidenheid karaktertipes rekening hou. Bunners ${ }^{34}$ onderskei die volgende hoortipes: die kritikus, die vennoot, die 
bewaarder en die bevryder. Die kritikus is die persoon wat vanuit 'n afstand weeg en oorweeg. 'n Neiging tot skeptisisme kom voor. Dié persoon beoefen geloof vanuit 'n kritiese perspektief. Die soort hoorder neig meer na die intellektuele as emosionele ingesteldheid. Die vennoot koester 'n heimlike angs vir ongeborgenheid en soek daarom kontak en invoeling met die prediker. Dié soort hoorder is veral op meelewing en versekering gerig. Die bewaarder het 'n vrees vir veranderinge. Hy hou van vertroue en die nadruk op die tradisie. Dié soort hoorder is dikwels die ywerige hoorder. Hy soek voorkeurerkenning en vertoon maklik twyfel. Emansipatoriese preke wat nuwe horisonne open en 'n appél op die wil maak, wat veranderinge inisieer en stimuleer, val in die bevryder se kraal. In die preek moet met die hoorder-kultuur rekening gehou word. Dit spreek vanself dat die pluraliteit van hoorders die kommunikasie van die preek kan bemoeilik.

Die hoordertipes staan in samehang met die prosesse van die menslike ontwikkeling en singewing. Dingemans ${ }^{35}$ onderskei op voetspoor van Fowler die volgende stadia in die geloofsontwikkeling:

"The synthetic faith". Hierdie geloofshouding is tipies van jongmense wat selfstandig begin dink en handel. Dit vind plaas deur middel van 'n kritiese en dikwels diepgaande evaluasie van alles wat hulle "tuis" ontvang het. Die proses begin so ongeveer van die veertiende jaar af en duur 'n aantal jare. $\mathrm{Na}$ die "afbreekperiode en beeldestorm" in die sogenaamde puberteit begin jongmense om hulle eie lewensvisie en lewenshouding op te bou en te vestig. In die proses kan 'n geloofsgemeenskap, ervaringe in die liturgiese viering en preke behulpsaam wees in die kritiese evaluering van die verlede en 'n perspektief skep op 'n nuwe sintese.

"The individuative reflective faith". Tydens hierdie periode kom mense tot "standpunte" en "oortuigings". Dit vorm die logiese afsluiting van die vorige periode. Daar word in die kerk na 'n eie standpunt gesoek deur dit teenoor ander standpunte te oorweeg. Dit is ook die tyd van polarisasie.

"The conjunctive faith". In dié fase leer die meeste mense om verskillende en selfs teenoorstaande visies te kombineer en in hulle lewe te integreer. Daar kom meer ruimte en openheid vir ander se menings en ook vir veranderinge in die persoonlike lewe.

"The universalizing faith". Ten slotte breek 'n periode van relativering en afstandname aan. Dit kan uitmond in 'n groot mate van verdraagsaamheid en wysheid. Maar dit kan ook lei tot 'n terugtrekking in die self en tot bitter kritiek op die buitewêreld.

Hierdie onderskeidinge is nuttig en bruikbaar. Dit moet net nie verabsoluteer word nie. Daar moet ook daarteen gewaak word om dit nie net liniêr te verstaan nie. Die een lei nie noodwendig tot die ander en sluit die vorige daarmee af nie. Daar is eerder 'n dinamiese interaksie tussen die fases werksaam.

In samehang met Fowler en Dingemans se fases in die geloofsproposisies kan die volgende aspekte in die geloofsontwikkeling ook onderskei word. 
(i) Die fase van blinde vertroue: In dié fase gaan dit om die vaste en sekere geloofsproposisies. In die geloof bevraagteken 'n mens niks nie, maar aanvaar net.

(ii) Die fase van vertwyfeling: In dié fase word teenstrydighede raakgesien. Alle sekerhede is voorlopig en relatief. Hierdie ervaring van die werklikheid word ook op die godsdiens oorgedra. Niks is meer vas en seker nie.

(iii) Die fase van onverbondenheid: Die fases staan nie los van mekaar nie, maar het ' $n$ invloed op mekaar. Die fase van onverbondenheid is ' $n$ reaksie op die vorige fase.

(iv) Die fase van fundamentele vertroue: In dié fase gaan dit om 'n kritiese geloofsverantwoording. In die proses word geloof geïnternaliseer en gekonkretiseer. Dit is by hierdie fase dat die hoorder moet uitkom.

Die hoorders bevind hulle nie almal in dieselfde fase nie. Die verskillende fases kan kommunikasiehindernisse vir die preek skep, maar dit kan ook geleenthede met die oog op kommunikasie skep. In die onderskeiding van die fases moet dit steeds in gedagte gehou word dat dit nie noodwendig liniêr verloop nie.

Pieterse 36 het daarop gewys dat sekere selektiewe prosesse die hoorervaring bemoeilik. Die hoorder verstaan die preek selektief binne sy eie werklikheid. Dit beteken dat die hoorder 'n selektiewe instelling ten opsigte van die preek het. Die hoorder het ook 'n selektiewe waarneming. Die hoorproses gaan verder met 'n selektiewe onthou gepaard. Al die komplekse prosesse mak dit nie vir die prediker makliker nie. Die preek word al meer'n onmoontlike moontlikheid.

Die hoorders leef tussen "eina en amen". Hulle sit in die kerk met hulle pyn, skuld en angs. Maar ook met hulle hoop, drome en verwagtinge ${ }^{37}$. Eintlik is hulle met die "eina en amen" op pad. Mense leef op die breuklyn van die geskiedenis. In hierdie opwegwees is daar nog die sugte en luste van die "ou mens", maar ook die sugte en vernuwing van die Gees (Rom 8; 12:1-2). Daar is sprake van verwagtinge en behoeftes in die opwegwees. Dingemans ${ }^{38}$ stel verwagtinge en behoeftes in 'n te sterk teenstelling as hy verklaar: "'Behoeften' duidt op onze 'natuurlijke' neigingen; verwachtingen worden gevoed door het historische verband waarin we zijn opgenomen". Daar kan eerder van 'n veelkantigheid van die gelowige se bestaan gepraat word. Om Christen te wees, beteken om met hoop gevul te wees. Maar hy leef nog op die aarde. Daarom het hy nog menslike behoeftes. Die behoeftes is nie ongeestelik nie. Daar moet op voetspoor van Maslow ${ }^{39}$ met die behoeftes op vyf vlakke rekening gehou word. Die onderste laag bestaan uit die fisiologiese behoeftes van eet en drink, rus en seksualiteit wat mense met diere in gemeen het. Op die tweede vlak lê die behoefte aan sekuriteit. Die derde laag is die behoefte aan liefde en behorenheid. Die vierde vlak is die behoefte aan erkenning en waardering. Die hoogste vlak is dié aan selfontplooiing en selfverwesenliking. $60 \%$ van die menslike behoeftes lê op die eerste twee vlakke; $30 \%$ op die derde vlak en $10 \%$ op die vierde en vyfde vlakke. Die kommunikasie van die preek word versteur deur die veelheid van behoeftes wat aangespreek moet word en die eensydige fokuspunt van menige preke (fokus op vlakke vier en vyf). 
Alles in ag genome is dit nie vreemd dat die preek op die weegskaal geplaas word nie. Miskien lê die behoud en die toekoms van die preek juis hierin.

\section{NOTAS:}

$1 \quad$ K-H Bieritz, "Predigt und rhetorische Kommunikation", K-H Bieritz, C Bunners, H Daewel et al, Handbuch der Predigt, Berlin 1990, 86.

$2 \quad$ K-H Bieritz, $a w, 86$.

$3 \quad$ K-H Bieritz, $a w, 86$.

4 C J A Vos, "Die ambagsman en sy beiteltjie", in: A J Smuts, C J A Vos, M Nel (reds), In gesprek oor die erediens, Pretoria 1990, 163.

5 D G Buttrick, Interpretation and preaching", Interpretation, 35/2 (1981) 46.

$6 \quad$ Suttrick, $a w, 47$.

7 G D J Dingemans, Als hoorder onder de hoorders... Een hermeneutische homiletiek, Kampen 1991, 21.

8 Dingemans, $a w, 21$.

9 H Hirschler, Biblisch predigen, Hannover 1988, 412; Dingemans, $a w, 21$.

10 H J C Pieterse, Die Woord in die werklikheid. 'n Teologie van die prediking, Pretoria 1988, 95-102; M Haustein, "Sprachgestalten der Verkundigung", KH Bieritz, C Bunners, H Daewel et al, Handbuch der Predigt, Berlin 1990, 467-470.

11 J A van der Ven, Entwurf einer empirischen Theologie, Kampen 1990, 55.

12 F B Craddock, As one without authority, Nashville 31987, 55.

13 Dingemans, $a w, 21$.

14 G D J Dingemans, De tijd van de verborgen God, 's Gravenhage 1990.

15 R Bohren, Predigtlehre, München $5_{1986,} 33$.

16 Die woord "Gottesfinsternis" kom van M Buber. H Jonker (Landingsplaatsen. Over theologie en leven, Nijkerk 1989, 171) verkies om eerder van "Godsnegatie of Godsontkenning" te praat.

17 W Verboom, "Prediking in een tijd van Godsverduistering", Theologia Reformata 34/2 (1991) 117; vgl G Heitink, in: G Dekker en K U Gäbler (reds), Sekularisatie in theologisch perspectief, Kampen 1987, 165; W H Velema, Nieuw zicht op Gereformeerde Spiritualiteit, Kampen 1990, 189-190. 
18 Vergelyk C J A Vos en J C Müller (reds), Mens en omgewing, Halfway House 1991.

19 Vergelyk C Bunners, "Die Hörer", K-H Bieritz, C Bunners, H Daewel et al, Handbuch der Predigt, Berlin 1990, 162-163.

20 Vos, $a w, 158$; Bieritz, $a w, 88$.

21 D J Bosch, Heil vir die wêreld, Pretoria 1979, 104-105.

22 Vir 'n oorsig oor die grondverskuiwings wat die geesteslewe van die mens ten nouste raak, vergelyk J Degenaar, Death of God, Cape Town, 1-20, 72-98; A van Seters, "The problem of preaching in the third millennium", Interpretation $45 / 3$ (1991) 267-269.

23 Dingemans, $a w, 1991,22$.

24 Dingemans, $a w, 1991,22$.

25 H J C Pieterse (Gemeente en prediking, Halfway House 1991, 97-128) het uitnemende navorsing oor die hermeneutiek van die hoorder gedoen. Vergelyk ook R Zerfass, Grundkurs Predigt. Spruchpredigt 1, Düsseldorf 1989, 69-75; Bunners, $a w, 1990,137-182$; Dingemans, $a w, 1991$, 51-65. Die eer kom Ernst Lange (Predigen als Beruf. Aufsätze zu Homiletik, Liturgie und Pfarramt, München 21987) toe dat hy die aandag op die hoorder in die preekproses gevestig het. Vergelyk in dié verband die voortreflike proefskrif van $\mathrm{J}$ H van der Laan, Ernst Lange en de prediking. Een inleiding in zijn homiletische theorie, Kampen 1989.

26 Van der Ven, $a w, 67-69$

$27 \quad$ Van der Ven, $a w, 67$.

28 Van der Ven, $a w, 68$.

$29 \quad$ Van der Ven, $a w, 68$

$30 \quad$ Van der Ven, $a w, 68$.

$31 \quad$ Van der Ven, $a w, 69$.

32 Bunners, $a w, 89$.

33 Dingemans, $a w, 1991,56$.

34 Bunners, $a w, 157$.

35 Dingemans, $a w, 1991,54$.

36 Pieterse, $a w, 1991,104-119$.

37 Dingemans, $a w, 1991,64$. 
38 Dingemans, $a w, 1991,65$.

39 A H Maslow, Motivation and personality, New York 21970. 